IZA DP No. 9557

The Moderating Effect of Higher Education on Intergenerational Spatial Inequality

Elise de Vuijst

Maarten van Ham

Reinout Kleinhans

December 2015 


\title{
The Moderating Effect of Higher Education on Intergenerational Spatial Inequality
}

\author{
Elise de Vuijst \\ Delft University of Technology \\ Maarten van Ham \\ Delft University of Technology and IZA \\ Reinout Kleinhans \\ Delft University of Technology
}
Discussion Paper No. 9557
December 2015

\author{
IZA \\ P.O. Box 7240 \\ 53072 Bonn \\ Germany \\ Phone: +49-228-3894-0 \\ Fax: +49-228-3894-180 \\ E-mail: iza@iza.org
}

Any opinions expressed here are those of the author(s) and not those of IZA. Research published in this series may include views on policy, but the institute itself takes no institutional policy positions. The IZA research network is committed to the IZA Guiding Principles of Research Integrity.

The Institute for the Study of Labor (IZA) in Bonn is a local and virtual international research center and a place of communication between science, politics and business. IZA is an independent nonprofit organization supported by Deutsche Post Foundation. The center is associated with the University of Bonn and offers a stimulating research environment through its international network, workshops and conferences, data service, project support, research visits and doctoral program. IZA engages in (i) original and internationally competitive research in all fields of labor economics, (ii) development of policy concepts, and (iii) dissemination of research results and concepts to the interested public.

IZA Discussion Papers often represent preliminary work and are circulated to encourage discussion. Citation of such a paper should account for its provisional character. A revised version may be available directly from the author. 


\title{
ABSTRACT \\ The Moderating Effect of Higher Education on Intergenerational Spatial Inequality
}

\begin{abstract}
It is well-known that socioeconomic outcomes and (dis)advantage over the life course can be transmitted from parent to child. It is increasingly suggested that these intergenerational effects also have a spatial dimension, although empirical research into this topic remains scarce. Previous research from Sweden and the United States shows that children who grow up in disadvantaged neighbourhoods experience long-term exposure to such neighbourhoods in their adult lives. This study contributes to the literature by examining to what extent educational attainment can break the link between parental neighbourhood disadvantage and the neighbourhood experiences of children as adults up to 12 years after leaving the parental home. We use longitudinal register data from the Netherlands to study a complete cohort of parental home leavers, covering 119,167 individuals who were followed from 1999 to 2012. Using sequence analyses as a visualisation method, and multilevel logit models, we demonstrate that children who lived in deprived neighbourhoods with their parents are more likely to live in similar neighbourhoods later in life than children who grew up in more affluent neighbourhoods. We find that intergenerational neighbourhood patterns of disadvantage can be discontinued when individuals attain higher education over time. Discontinuation is however less prevalent among individuals from ethnic minority groups.
\end{abstract}

JEL Classification: $\quad$ 130, J60, P46, R23

Keywords: intergenerational inequality, neighbourhood effects, deprived neighbourhoods, neighbourhood histories, educational attainment, longitudinal data, sequence analysis, the Netherlands

Corresponding author:

Elise de Vuijst

OTB - Research for the Built Environment

Faculty of Architecture and the Built Environment

Delft University of Technology

P.O. box 5043

2600 GA, Delft

The Netherlands

E-mail: E.deVuijst@tudelft.nl 


\section{Introduction}

The residential environment has increasingly been argued to affect individual-level outcomes in life, through supposed neighbourhood effects. Deprived neighbourhoods in particular are assumed to have a negative impact on the life chances of their residents, with spatial poverty concentrations functioning as an amplifier of the consequences of individual disadvantages (for a compilation see Ellen \& Turner, 1997; Sampson et al. 2002; Galster 2002, 2012; Dietz 2002; Friedrichs \& Blasius 2003; Crowder \& South 2003; Durlauf 2004; Wilson, 2012[1987]; van Ham \& Manley 2012; van Ham et al. 2014). It has repeatedly been suggested that individuals' long-term neighbourhood experiences are crucial in determining the possible causal connection between neighbourhood characteristics and individual outcomes (Quillian 2003; Sharkey \& Elwert 2011; Musterd et al. 2012; Galster 2012; Hedman et al. 2013). Individual outcomes are likely not only affected by the current residential location, but also by all previous experiences in the individual residential history. Hence, researchers have argued that individuals and their neighbourhoods must be seen as fundamentally dynamic, rather than static entities over the life course. Therefore, the full impact of neighbourhoods on individual outcomes cannot be captured when leaving out of consideration the temporal context to spatial patterns of deprivation (Sampson et al. 2002; van Ham et al. 2014). Nevertheless, most studies to date have not conducted longitudinal analyses of individual neighbourhood histories, often due to a lack of geo-coded data over longer periods of time. This limitation entails that the bulk of studies into neighbourhood effects has had to use point-in-time measures of neighbourhood characteristics, and that researchers have thus largely overlooked the temporal dimension of neighbourhood effects (Sharkey \& Elwert 2011; van Ham et al. 2014).

The argument for a dynamic interpretation of individuals and their neighbourhood history over the life course is reinforced by the body of research on intergenerational continuity of disadvantage. Sociological literature has stressed the continuity of poverty patterns across generations, suggesting great difficulty in upward social mobility throughout life for those born in the lowest social classes (Blanden et al. 2005; Bloome 2014). The neighbourhood, however, as a potential spatial dimension to such intergenerational transmission patterns, has largely been left out of consideration. To our knowledge, there are only a few studies that have examined parent-to-child transfer of disadvantageous neighbourhood characteristics, conducted on Swedish and United States' national data (Vartanian et al. 2007; Sharkey \& Elwert 2011; Hedman et al. 2013; van Ham et al. 2014). These authors have found that even in adulthood, up to almost two decades after leaving the parental home, parental neighbourhood characteristics are a strong predictor for the neighbourhood history of their children and for the length of their exposure to deprived neighbourhoods over the life course. Furthermore, for ethnic minority groups, these patterns were stronger than for majority groups (ibid.).

In this study, we use data from the Netherlands to examine the extent to which growing up in a deprived neighbourhood influences the neighbourhood histories of adults. We take an explicit life course approach to neighbourhood effects by assessing the temporal context to intergenerational spatial inequality. Our main contribution to the literature is that we investigate whether educational attainment can break the link between parental neighbourhood disadvantage and the neighbourhood experiences of children as adults. As education has the potential to positively affect income levels and upward social mobility, we expect that higher education will moderate the effect of the deprived parental neighbourhood on individual neighbourhood outcomes. As individuals from non-Western ethnic minority groups were previously shown to be most likely to live in continuous poverty before and after 
leaving the parental home (van Ham et al. 2014), we further assess whether the moderation of an intergenerational neighbourhood effect by educational attainment is weaker for ethnic minority groups than for others.

We make use of individual-level, geo-coded longitudinal register data provided by Statistics Netherlands. These data allow us to track a complete cohort (not a sample) of parental home leavers from 1999 to 2012. We follow 119,167 Dutch inhabitants, and are able to construct and assess their individual neighbourhood histories, as well as their key demographic and socio-economic characteristics. We use sequence analyses to display the most common neighbourhood history patterns over the measurement period, and fit multilevel logit models to determine the effect of the parental neighbourhood on personal residential outcomes, as well as the moderating effect of education.

\section{Theoretical background}

Over the past decades, alleged neighbourhood effects have been reported on individual outcomes from childhood and adolescence up into adulthood, ranging from socioeconomic attainment to individual wellbeing and health. For children and adolescents, literature suggests an effect of the residential environment on school dropout rates and childhood achievement, child maltreatment, delinquency, and teenage pregnancy (Overman 2002; Brooks-Gunn 1997a, 1997b; Galster et al. 2007; Crowder \& South 2003). For adults, spatially concentrated disadvantage was shown to affect income levels and social mobility patterns, social exclusion, transition rates from welfare to work, and deviant behaviour and delinquency (Van der Klaauw \& Ours 2003; Simpson et al. 2006; Buck 2001; Galster et al. 2007; Galster et al. 2010; Friedrichs \& Blasius 2003). Nevertheless, an essential and persistent problem to the body of neighbourhood effects literature, is the fact that most research to date, including examples listed above, has used either cross-sectional data or short periods of longitudinal data in their analyses (van Ham et al. 2014; Clark \& Ledwith 2005; Geist \& McManus 2008; Quillian 2003; Sharkey \& Elwert 2011). For this reason, conclusions on neighbourhood effects are commonly drawn from single point-in-time measures of individuals' current neighbourhood characteristics and their instantaneous effect on current individual-level outcomes (van Ham et al. 2014). However, it makes strong intuitive sense to assume that a lengthy exposure to deprived neighbourhoods will have a stronger negative effect on individual outcomes than exposure for short periods of time. For socioeconomic outcomes, such as income and educational attainment, similar mechanisms have indeed been identified, where experiences over time were shown to have a strong cumulative effect on current individual outcomes, and patterns could be discerned between generations (Blanden et al. 2005; Bloome 2014). For this reason, studies using single point-in-time measures of neighbourhood characteristics are increasingly criticised. It is argued that in order to assess whether individuals' chances are truly impaired by where they live, it is vital to take into consideration their full neighbourhood histories, rather than focus on their current residential location alone (Quillian 2003; Sharkey \& Elwert 2011; Musterd et al. 2012; Galster 2012; Hedman et al. 2013; van Ham et al. 2014). Several researchers have argued for a step forward in neighbourhood effects research by tackling this problem.

\section{Introducing a life course approach to neighbourhood effects}

We argue that a life course approach to neighbourhood effects and thorough longitudinal research must be the starting point in bringing the neighbourhood effects literature forward 
(Manley \& van Ham 2010; Small \& Feldman 2012; van Ham et al. 2014). In relation to the residential environment, life course research has predominantly been applied in residential mobility studies into housing careers over time (Clark \& Huang 2003; Feijten \& Mulder 2005). For example, individuals receiving welfare support, or living in public housing, were shown to experience less upward mobility across neighbourhoods over time, as did homeowners (South \& Crowder 1997; Vartanian et al. 2007). Meanwhile, an increase in socioeconomic resources and status was shown to increase the chances of upward neighbourhood mobility (Clark et al. 2003). Ethnic minorities were repeatedly shown to live in neighbourhoods with higher concentrations of poverty, and worse social provisions and services, than other residents over the life course (Crowder \& South 2005; Vartanian et al. 2007; Simpson \& Finney 2009; van Ham et al. 2014). Additionally, children were shown to prefer similar types of accommodation to their parents over time with regard to rental versus privately owned housing, thus affecting their choice of neighbourhood (Kurz 2004; Helderman \& Mulder 2007; Feijten et al. 2008).

A vital notion to the life course approach is that any point in an individual's biography must be seen in the light of foregoing experiences in their lives. It is thus put forward that seemingly separate life events, in relation to experiences in the household, housing, education and the labour market, are in fact inescapably interrelated and can accumulate in their effect on personal outcomes over time (Dykstra and van Wissen 1999; Feijten 2005; Feijten et al. 2008). When using single point-in-time measures of neighbourhood characteristics, researchers cannot grasp individuals' full personal biographies, visualise their unique sequence of life events over time, or truly assess the relative or cumulative importance thereof (Feijten 2005; Geist \& McManus 2008; van Ham et al. 2014). Applied to our study of intergenerational spatial inequality, a life course approach enables us to examine the manner in which neighbourhood experiences are embedded in larger individual neighbourhood histories, the order and timing of these occurrences, as well as their duration (Giele \& Elder 1998; Feijten 2005; Aisenbrey \& Fasang 2010).

\section{The impact of the parental neighbourhood}

The parental neighbourhood can play an important role in determining the neighbourhood experiences of children after leaving the parental home, for a number of reasons. First of all, parental income has repeatedly been shown to be strong predictor for individual attributes related to income, including income levels and sources, homeownership, and further socioeconomic attainments over the life course (Becker \& Tomes 1979; Solon 2002; D'Addio 2007). Therefore, as all such attributes were shown to influence individual mobility across neighbourhoods over time, and selection into deprived neighbourhoods, parental transmission of neighbourhood characteristics may in part result from these income mechanisms. Second of all, children are socialised into similar norms and values to those of their parents, and the cultural traits of the groups and individuals their parents associate with in everyday life (Galster 2012). Therefore, in individuals' formative period, norms and attitudes towards customs and social processes are largely inherited from their parents and are dependent on the contacts and environment to which they are exposed. While norms continuously develop over the life course, acting in accordance to parental convictions early on in life can have longlasting consequences to individual outcomes over time. This transmission of norms could accordingly play an important role in the transmission of neighbourhood characteristics between generations, independent to the transmission through income mechanisms. Norms can determine attitudes towards employment, income, and other socioeconomic factors involved in shaping individual neighbourhood histories and housing options (Bisin \& Verdier 
1998; for an extensive discussion see Galster 2012). Previous studies conducted in Sweden and the United States do suggest an independent effect of the parental neighbourhood on the neighbourhood outcomes of their children, and attribute their results to such transmission and inheritance mechanisms (Vartanian et al. 2007; Sharkey \& Elwert 2011; van Ham et al. 2014). Additionally, however, after leaving the parental home, individuals may prefer similar types of neighbourhoods to those of their parents because the composition and facilities are familiar to them, or they want to be close to their family.

Despite the various possible influences of the parental neighbourhood, we strongly expect that as an individual progresses through life and their neighbourhood history, their personal rather than inherited attributes and socioeconomic resources will become increasingly important to their personal outcomes. One important attainable resource over time, which can strongly determine individual outcomes in life, is education. As education can positively affect income levels and upward social mobility, educational attainment has the potential to break the link between parental neighbourhood disadvantage and the neighbourhood experiences of children after leaving the parental home. As such, educational attainment can be seen as a means to escape the determining impact of the parental neighbourhood on individual neighbourhood outcomes over the life course.

\section{Hypotheses}

Based on the discussion of literature above, as well as recent findings in Sweden and the United States (Sharkey \& Elwert 2011; Hedman et al. 2013; van Ham et al. 2014), we expect that individuals from a deprived parental neighbourhood will have a higher probability of spending time and ending up in deprived neighbourhoods after leaving the parental home, compared to individuals from a more affluent parental background. In this study, our main hypothesis reads that intergenerational spatial inequality can in time be significantly weakened, or even discontinued, by individuals' educational attainment over the life course. Finally, as ethnic minorities have been suggested to be less likely to translate resources into mobility across neighbourhoods, we examine whether educational attainment is a stronger moderator of an intergenerational neighbourhood effect for ethnic majorities than for ethnic minorities.

\section{Data}

For this study, data was derived from the System of Social statistical Datasets (SSD hereafter), which is an integrated, longitudinal database of numerous surveys and administrative registers provided by Statistics Netherlands. The SSD registers contain core demographic, socio-economic and geographic observations on the entire Dutch population tracked from 1995 to 2014. The SSD provides information on family background (Bakker et al. 2014), which allows us to distinguish personal and geographic parental characteristics for individuals in our selected subpopulation. All available registers are linked at the individual level, which makes these data exceptionally suitable for a visualisation of individual neighbourhood histories. Additionally, using the SSD, we faced hardly any attrition within our subpopulation over time, as it is not a sample. Since 1999, in comparison to previous years, the number and quality of the socio-economic and demographic data in the SSD substantially increased. For the most recent years, not all registers have been released in full for public use. For this reason, the measurement period for this study will range from 1999 to 2012. Individuals can thus be followed for a period of 14 years. 
In this study, we made a number of population selections in order to construct a suitable subgroup for whom to examine individual neighbourhood histories. To establish our subpopulation, first of all, we selected individuals from ten different birth cohorts; born within 1974 to 1983. We thus restricted the selection to individuals aged 16 to 25 in 1999 $(\mathrm{N}=2,389,031)$. Second of all, individuals who lacked information on parental characteristics and residential location, and those who died or emigrated during the measurement period, were excluded from our selection (remaining: $\mathrm{N}=1,810,449$ ). Third of all, we took into consideration those individuals for whom we had full demographic, socioeconomic and residential information, and who lived with their parents in 1999, and had left the parental home in the following year (remaining: $\mathrm{N}=154,189$ ), thus starting their individual neighbourhood trajectory. The characteristics used to define anchors' neighbourhood experiences before leaving the parental home are thus based on one year of observations, namely 1999. While this may produce bias in representing the entire childhood neighbourhood experience, previous research has shown that neighbourhood characteristics are highly correlated throughout childhood (Vartanian et al. 2007; Kunz et al. 2003; Manley et al. 2013). For this reason, using a singular year of parental neighbourhood characteristics is unlikely to offset the validity of our results. Finally, if both partners in a household (registered partnership or marriage) were present in our subpopulation, i.e. if both fitted the initial selection criteria described above, we dropped one of them at random. We subsequently reorganised the data into person-year format. The total number of individual records after this selection consisted of 119,167 Dutch inhabitants (N), and 1,668,338 year-files ( $N$. obs) accordingly, over the 14-year measurement period. Table I provides an overview of the core descriptive statistics on the individual-level for our subpopulation.

Table I. Descriptive statistics of anchor population in 1999 (in the parental home), 2000 (having left the parental home), 2006, and 2012.

\begin{tabular}{lllll}
\hline & 1999 & 2000 & 2006 & 2012 \\
\hline Age Mean (Std. dev.) & $20.59(2.61)$ & $21.58(2.61)$ & $27.57(2.60)$ & $33.57(2.61)$ \\
Share males & 45.85 & 45.85 & 45.85 & 45.85 \\
Ethnic background & & & & \\
$\quad$ Dutch & 81.50 & 81.50 & 81.50 & 81.50 \\
$\quad$ Moroccan & 3.02 & 3.02 & 3.02 & 3.02 \\
$\quad$ Turkish & 3.48 & 3.48 & 3.48 & 3.48 \\
$\quad$ Surinamese & 2.50 & 2.50 & 2.50 & 2.50 \\
$\quad$ Antillean/Aruban & 0.62 & 0.62 & 0.62 & 0.62 \\
$\quad$ Other non-western & 2.27 & 2.27 & 2.27 & 2.27 \\
$\quad$ Other western & 6.62 & 6.62 & 6.62 & 6.62 \\
Share students & 46.48 & 37.13 & 6.95 & 0.84 \\
Level of education & & & & \\
$\quad$ Low & 84.00 & 76.56 & 57.32 & 53.42 \\
$\quad$ High & 16.00 & 23.44 & 42.68 & 46.58 \\
Share with children & .50 & 2.93 & 28.31 & 57.57 \\
Share single household & & 42.28 & 28.59 & 22.70 \\
Share couple/married & - & 40.98 & 59.59 & 71.62 \\
Share primary income from benefits & 13.48 & 8.04 & 12.39 & 17.48 \\
Share primary income from work & 86.52 & 91.96 & 87.61 & 82.52 \\
Income (1000 EU) Mean (Std. dev.) & 10.37 (9.90) & $14.21(9.99)$ & $25.13(16.92)$ & $33.99(26.47)$ \\
Housing tenure & & & & \\
$\quad$ Homeowner & & 41.06 & 54.17 & 64.57 \\
$\quad$ Rent & 36.79 & 58.88 & 45.55 & 35.14 \\
Residential location & & & & \\
\hline & & & & \\
\hline
\end{tabular}




\begin{tabular}{lllll}
\hline 4 biggest municipalities & 10.12 & 18.07 & 18.68 & 18.53 \\
35 following biggest municipalities & 24.53 & 37.71 & 32.62 & 29.62 \\
Other municipalicities & 65.36 & 44.21 & 48.70 & 51.86 \\
$\mathrm{~N}$ & 119167 & 119167 & 119167 & 119167 \\
\hline
\end{tabular}

Note: Unless otherwise indicated, values are reported in percentages. As some variables contain missing or unknown values, not all values will sum up to $100 \%$

aAll anchors were registered as 'child within the parental home' in 1999, the 'single household' category was therefore not applicable in this year

${ }^{\text {b}}$ The homeowner category refers to the record of the building in the national housing registers, not the individual residing in it. Therefore, the homeowner category may include individuals who rent from a landlord/lady who did not officially declare their property to be let out to tenants

'The housing tenure in 1999 refers to the parental home

The SSD provides unique geo-coded information, including an array of spatial levels differing in size. In this study, we selected 500x500 meter grids to define our neighbourhood boundaries. The Netherlands consist of 34,094 inhabited 500x500 meter grid cells containing 496 inhabitants on average. These grids are smaller than most standard Dutch administrative units, such as postal code areas, and are thus more likely to depict inhabitants' perceived neighbourhood boundaries and direct neighbourhood environment. Using these grids further enables us to compare equally-sized, smaller spatial units throughout the Netherlands, the boundaries lines of which are constant over time. For this reason, while grids are not defined based on logical structural, and infrastructural characteristics, but on assigned coordinates of square geographic areas, they nonetheless form a suitable spatial scale on which to construct, measure, and compare neighbourhood histories.

As we examine intergenerational continuity of neighbourhood status over time, our primary neighbourhood characteristic is the concentration of poverty within the grid cell. Personal income was defined as the sum of income from a variety of sources, consisting of wages, benefits, and student scholarships. On data containing the economic characteristics and income distribution of the entire Dutch population, we constructed income quintiles, the last of which contained all inhabitants who fell into the lowest 20 percent of incomes. Subsequently, we constructed neighbourhood quintiles, in which poverty concentration was defined based on the share of low-income neighbours. Neighbourhoods in the first income quintile have the lowest concentration of poverty, while those in the fifth quintile have the highest concentration of poverty. We thus refer to neighbourhoods in the latter category as deprived neighbourhoods. Tables IIa and IIb show a number of basic descriptive statistics at the quintile-level, at the time of living in the parental home (1999), and halfway through the measurement period (2006).

Table II. Basic descriptive statistics on the neighbourhood quintile-level in 1999 (in the parental home), and in 2006, halfway through the measurement period

\begin{tabular}{rllll}
\hline & \multicolumn{2}{c}{1999} & \multicolumn{2}{c}{2006} \\
\hline & $\begin{array}{l}\text { \% low-income } \\
\text { inhabitants }\end{array}$ & $\begin{array}{l}\text { \% ethnic } \\
\text { minorities }\end{array}$ & $\begin{array}{l}\text { \% low-income } \\
\text { inhabitants }\end{array}$ & $\begin{array}{l}\text { \% ethnic } \\
\text { minorities }\end{array}$ \\
\cline { 2 - 5 } Neighbourhood Mean(Std. dev.) & & & & \\
1. Low poverty concentration & $13.56(3.54)$ & $4.63(5.30)$ & $14.43(4.11)$ & $6.74(4.74)$ \\
2. & $17.74(.69)$ & $5.58(7.00)$ & $17.90(2.39)$ & $6.81(5.34)$ \\
3. & $19.84(.57)$ & $5.48(7.05)$ & $19.95(2.41)$ & $7.62(6.52)$ \\
4. & $21.97(.69)$ & $6.77(9.75)$ & $22.10(2.52)$ & $9.07(8.34)$ \\
$5 . \quad$ Deprived neighbourhood & $27.39(6.57)$ & $10.50(15.96)$ & $26.63(6.17)$ & $13.27(12.66)$ \\
$\mathrm{N}$ & 119167 & 119167 & 119167 & 119167 \\
\hline
\end{tabular}


The descriptive results in table II and II illustrate that deprived neighbourhoods indeed contain the highest overall share of low-income inhabitants, and further house the highest concentrations of ethnic minorities.

\section{Analytic strategy}

In this study, we used sequence analyses to visualise individual neighbourhood residence in the constructed income-quintiles over time. In recent years, sequence visualisation has become increasingly popular in social research, and a small number of neighbourhood studies have used this method before to investigate individual neighbourhood histories and track residential change over a measurement period (Coulter \& van Ham 2013; van Ham et al. 2014). We used the SQ-Ados bundle of Stata programs in Stata 12 to create individual sequences for the anchor population. Each individual person-year observation on the neighbourhood quintile forms an element in the sequence of a respondent (Brzinsky-Fay et al. 2006). In theory, each horizontal line in the sequence plots shows the entire 14-year neighbourhood history of an individual within our subpopulation, from 1999 to 2012 (see figures I a-c). In practice however, due to pixilation restrictions, the figures show larger population trends in neighbourhood histories rather than identifiable personal tracks. As stated, the neighbourhood quintile in 1999 is used to represent the parental neighbourhood characteristics. All five neighbourhood quintiles were given a separate colour-coding to discern their difference in poverty concentration. A change of colour in an individual timeline from one year to the next thus indicates a residential move to a grid area with a higher or lower concentration of low-income neighbours compared to the previous year. If there is no change of colour between years in the sequence, either the individual has not experienced a residential move, or the individual has moved but their neighbourhood quality has not changed.

In addition to the visualisation techniques, in order to examine how neighbourhood histories are likely to develop after leaving the parental home, we estimated neighbourhood outcomes over the measurement period using multilevel logit models. The dependent variable in these models in the probability of residing in a deprived neighbourhood after leaving the parental home. Using a dichotomous dependent variable, we fitted xtlogit models for two points in the measurement period, 2006 and 2012, which provided us with logistic estimates. In order to examine intergenerational neighbourhood continuity over time, the most important independent variable in our analyses is the parental neighbourhood quintile, measured in 1999. In model 2, we add an interaction between deprived parental neighbourhoods (in quintile 5) and individuals' personal educational attainment, in order to check for a moderating effect of education on the influence of childhood experiences with poverty concentration. Subsequently, in model 3, we add a three-way interaction between the deprived parental neighbourhood (quintile 5); individuals' personal educational attainment; and whether the individual belongs to an ethnic minority group. By doing so, we are able to check whether an effect of personal educational attainment on the expected intergenerational transmission of deprived neighbourhood characteristics is stronger for non-ethnic minorities in our subpopulation, as opposed to those from an ethnic minority. In other words, this model will enable us to examine whether non-ethnic minorities are more likely to discontinue poverty patterns across generations through positive accumulation of individual socioeconomic resources over the life course compared to individuals from an ethnic minority. 
A selection of individual and household characteristics, described (among others) in table I above, are included as further independent variables throughout the models. Socioeconomic observations include individuals' highest level of education over time; their annual income; and their type of housing tenure (when available; see table I). Concerning the anchors' educational level, the SSD contains information on degrees obtained in higher education from 1986 onwards (Bakker et al. 2014). Low and middle levels of education however were not officially recorded until 2003. Therefore, for our subpopulation, we have reliable integrated data on anchors' attainment of higher education (i.e. higher vocational or professional (HBO), college, or university), but we cannot distinguish low and middle level degrees. We thus include a dummy for higher education (yes/no) in our models, both as a main effect and in the interactions with the parental neighbourhood characteristics and ethnicity. We further include the individual's gender; whether they are single; and whether they belong to one of the main ethnic minority groups in the Netherlands (i.e. Moroccan, Turkish, Surinamese, and Dutch Antillean/Aruban). Finally, we add individuals' age, and the income of the parental household in 1999 as controls in the models.

\section{Results}

Sequence analyses. Figure I (a) and (b) show the 14-year neighbourhood histories of two random samples of 5000 individuals in our subpopulation, from 1999 to 2012, organised by the parental neighbourhood quintiles with the lowest (blue segments) and highest (grey segments) concentrations of poverty accordingly (quintile 1 and 5). At the beginning of our measurement period, there is a slight overrepresentation in our subpopulation of individuals residing with their parents in a deprived neighbourhood (24.3\%) compared to other neighbourhood types. For individuals from a relatively affluent parental background, displayed in figure 1(a), we see that a large part continue to live in neighbourhoods with the lowest concentration of poverty when leaving the parental home in 2000, but that the majority move into neighbourhoods with higher concentrations of poverty, some deprived. Such residential changes can be expected for a young subpopulation, which likely consists of students and starters on the labour market. In subsequent years, the majority of this group climbs back up the quintile ladder and begin to reside in more affluent neighbourhoods once more. The column right of the figure shows the individuals' residential locations sorted by quintile type in 2012. At the final measurement point, the distribution of individuals over the neighbourhood types is relatively equal for quintiles 2 to 5 , with a distinct overrepresentation of individuals residing in quintile 1 , with the lowest concentration of poverty. Nevertheless, the majority of individuals are shown not to have reached the same neighbourhood type as their parents 12 years after starting their individual residential histories. The sequence plot thus suggests that individuals from an affluent background experience upward social residential mobility after leaving the parental home, but that it takes a lot of time to reach the same neighbourhood type as their parents, if they do at all. 
Figure I. Sequence plot on patterns of individual neighbourhood histories 1999-2012 (on a sample of 5000 individual histories) of those leaving the parental home in 1999-2000, by parental neighbourhood quintiles (1: lowest poverty concentration (a), and 5: highest poverty concentration (b))

(a)

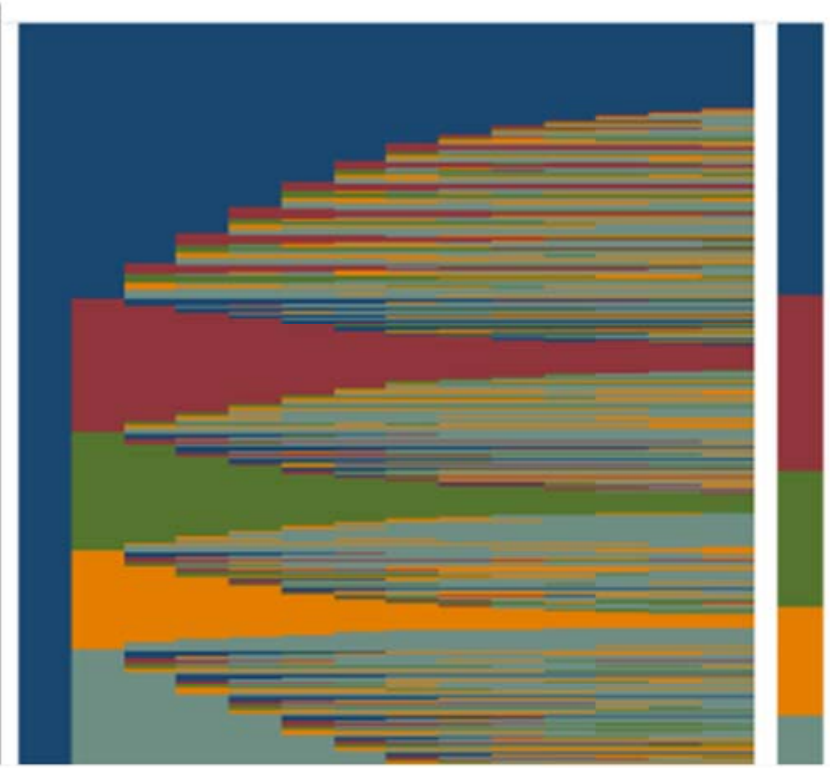

(b)

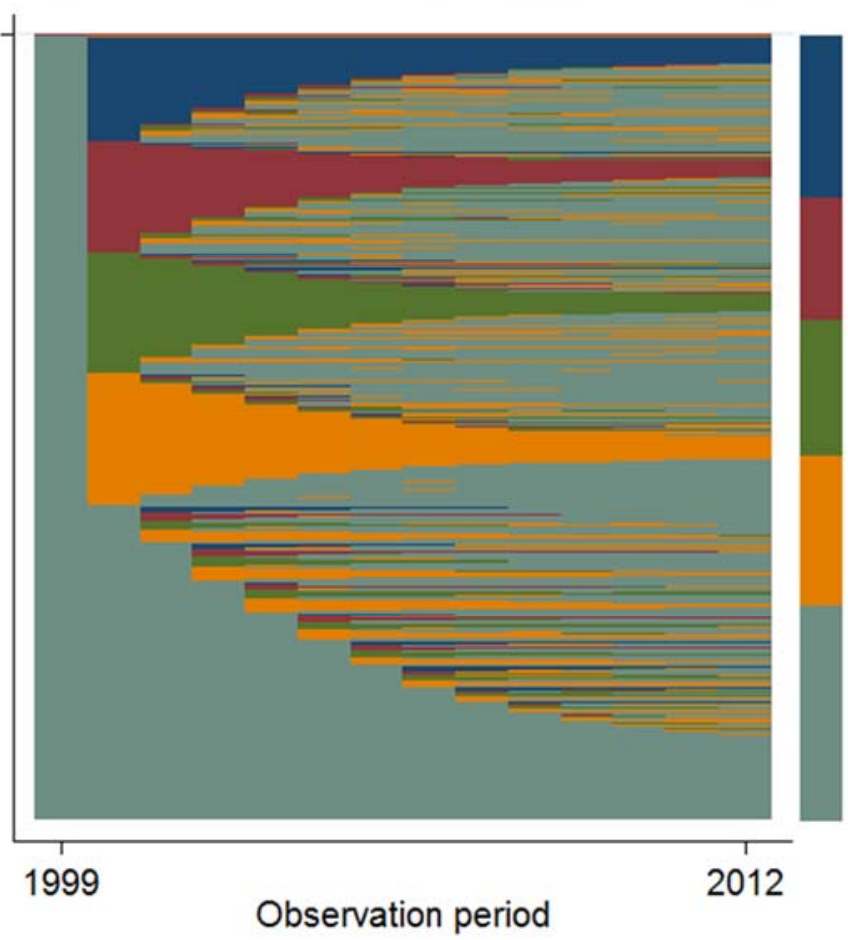

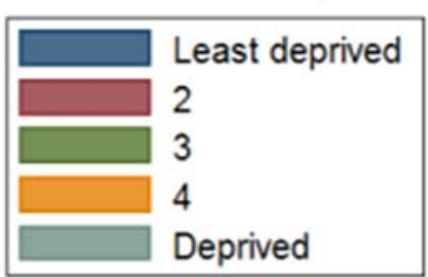

\begin{tabular}{|l|}
\hline$\square$ Least deprived \\
\hline 2 \\
3 \\
\\
$\square$ \\
$\square$ Deprived \\
\hline
\end{tabular}


For individuals from a deprived parental neighbourhood in figure I (b), at first glance, the residential trajectories show a similar pattern to those of individuals in figure I (a). For this subgroup, a large group of individuals remain to reside in poverty quintiles after having left the parental home, while a small majority initially switches neighbourhood types. When taking a closer look at the sequence plot however, the dominance of the grey (deprived) segments throughout the individual trajectories, especially towards the end of the 12-year measurement period, is striking compared to the lack of blue (affluent) segments around the same time in figure I (a). Again, the column right of the figure shows the individuals' residential locations sorted by quintile type in 2012, and interestingly, there is only a slight overrepresentation of individuals residing in deprived neighbourhoods.

Table III. Residence in neighbourhood quintiles (2000-2012) by parental neighbourhood quintile (1999)

\begin{tabular}{lccccc}
\hline $\begin{array}{l}\text { Parental neighbourhood } \\
\text { quintile in 1999 }\end{array}$ & \multicolumn{5}{c}{ Exposure to deprived neighbourhood over the measurement period 2000-2012 } \\
\hline & Quintile 1 & Quintile 2 & Quintile 3 & Quintile 4 & Quintile 5 \\
\cline { 2 - 6 } & & & & & \\
Quintile 1 & 38.56 & 18.90 & 15.16 & 13.21 & 14.16 \\
Quintile 2 & 22.67 & 30.24 & 17.24 & 14.75 & 15.10 \\
Quintile 3 & 19.98 & 18.02 & 28.62 & 17.04 & 16.34 \\
Quintile 4 & 17.72 & 16.30 & 17.47 & 29.13 & 19.38 \\
Quintile 5 & 15.06 & 13.85 & 15.37 & 17.91 & 37.82 \\
\hline
\end{tabular}

Note: Unless otherwise indicated, values are reported in percentages.

Table IV. Descriptive statistics on the most frequent quintile sequence patterns for anchor subgroup over the observation period 1999-2012

\begin{tabular}{|c|c|c|c|c|c|c|c|c|c|c|c|c|c|c|c|}
\hline \multicolumn{14}{|c|}{ Sequence pattern } & Frequency & $\%$ occurrence \\
\hline \multicolumn{16}{|c|}{ Neighbourhood quintile } \\
\hline 5 & 5 & 5 & 5 & 5 & 5 & 5 & 5 & 5 & 5 & 5 & 5 & 5 & 5 & 2983 & 21.05 \\
\hline 1 & 1 & 1 & 1 & 1 & 1 & 1 & 1 & 1 & 1 & 1 & 1 & 1 & 1 & 1928 & 13.60 \\
\hline 4 & 4 & 4 & 4 & 4 & 4 & 4 & 4 & 4 & 4 & 4 & 4 & 4 & 4 & 1579 & 11.14 \\
\hline 2 & 2 & 2 & 2 & 2 & 2 & 2 & 2 & 2 & 2 & 2 & 2 & 2 & 2 & 1306 & 9.22 \\
\hline 3 & 3 & 3 & 3 & 3 & 3 & 3 & 3 & 3 & 3 & 3 & 3 & 3 & 3 & 1305 & 9.21 \\
\hline 2 & 1 & 1 & 1 & 1 & 1 & 1 & 1 & 1 & 1 & 1 & 1 & 1 & 1 & 1155 & 8.15 \\
\hline 3 & 1 & 1 & 1 & 1 & 1 & 1 & 1 & 1 & 1 & 1 & 1 & 1 & 1 & 1045 & 7.37 \\
\hline 4 & 1 & 1 & 1 & 1 & 1 & 1 & 1 & 1 & 1 & 1 & 1 & 1 & 1 & 1022 & 7.21 \\
\hline 4 & 5 & 5 & 5 & 5 & 5 & 5 & 5 & 5 & 5 & 5 & 5 & 5 & 5 & 957 & 6.75 \\
\hline 5 & 4 & 4 & 4 & 4 & 4 & 4 & 4 & 4 & 4 & 4 & 4 & 4 & 4 & 892 & 6.29 \\
\hline Total & & & & & & & & & & & & & & 14172 & 100.00 \\
\hline
\end{tabular}

Note: one element in the sequence represents one year in the measurement period. Numbers represent the quintile type; from 1 with the lowest concentration of poverty, to 5 with the highest concentration of poverty.

Additionally, however, while a large number of trajectories for individuals from a wealthy parental background show episodes of residence in a neighbourhood with a low to intermediate concentration of poverty (red and green segments), these patterns are less common for individuals from a deprived parental background. What this visualisation thus shows, is that individuals from an affluent background are most likely to experience upward social mobility after leaving the parental home, even after having resided in neighbourhoods 
with a higher concentration of poverty at one point in time, compared to individuals from a deprived neighbourhood background. Individuals from a deprived parental neighbourhood, are not only less likely to experience upward neighbourhood mobility, but also display a high level of lengthy or continuous residence in a deprived neighbourhood up to 12 years after leaving the parental home. These patterns are further illustrated and supported by the results in tables III and IV, which accordingly show the percentage of years that individuals are exposed to each of the five neighbourhood quintile types over the measurement period (by the parental neighbourhood quintile in 1999), and the ten most frequent sequence patterns of our subpopulation of home leavers.

The results in table III show that individuals who come from a more affluent parental background, and thus lived in a neighbourhood with a low concentration of poverty in 1999, are most likely to spend time in similarly categorised neighbourhoods (quintile 1) during their own residential history up to 12 years after leaving the parental home (38.6\% of years over the measurement period). Comparatively, individuals from a deprived parental neighbourhood (quintile 5) are least likely to reside to reside in low poverty concentration neighbourhoods (only $15.1 \%$ of years over the measurement period). The other way around, the same pattern can be identified. The results show that individuals from a deprived parental neighbourhood are most likely to reside in deprived neighbourhoods themselves after leaving the parental home during the entire measurement period (37.8\% of 12 years), compared to individuals from a more affluent background (14.2\% of 12 years). Adding to these results, table IV shows that individuals are not only most likely to spend time in similar neighbourhoods to those of their parents, but that individual residential patterns are in fact highly persistent with regard to continued residence in a neighbourhood quintile type, i.e. 14 years of exposure to one type of neighbourhood before and after leaving the parental home. The descriptive results in table IV, on our entire anchor population, show that unremitting residence in a deprived neighbourhood is by far the most common residential pattern of all.

The results from the sequence analyses and accompanying tables show a clear relationship between the parental neighbourhood and exposure to each of the five constructed categories of poverty concentration, as well as the persistence of residence within one of these categories in individuals' residential histories after leaving the parental home. Particularly for individuals from a deprived parental neighbourhood, exposure to poverty and lengthy residence in deprived neighbourhoods are highly prevalent throughout life. Overall, these findings strongly resemble the patterns previously identified in Sweden (Hedman et al. 2013).

Multivariate analyses]. Table $\mathrm{V}$ shows the results from the multilevel logistic regression models on the effect of the parental neighbourhood on individuals' risk of residing in deprived neighbourhoods in their own residential trajectory over the measurement period. Both the 2006 and 2012 model results indicate that the parental neighbourhood is an important predictor of their children's residential location after leaving the parental home. The parental neighbourhoods with the highest, and second-to-highest concentrations of poverty have a positive significant effect on residence in a deprived neighbourhood later in life, with the former showing the strongest effect overall. Importantly, while the deprived parental neighbourhood has a slightly stronger effect in 2006 compared to 2012, it remains the most important predictor for living in poverty concentration up to 12 years after leaving the parental home. These results thus match our expectations, and the sequence descriptives and visualisations presented above. The effects of the parental neighbourhood categories hold throughout the models after adding the relevant moderating factors and controls, including parental income. 
Table V. Multilevel logit models on living in a deprived neighbourhood (quintile 5), 6 and 12 years after leaving the parental home

\begin{tabular}{|c|c|c|c|c|c|c|c|c|c|c|c|c|}
\hline \multirow[b]{3}{*}{ Parental neighbourhood Q2 (ref = Q1) } & \multicolumn{6}{|c|}{2006} & \multicolumn{6}{|c|}{2012} \\
\hline & \multicolumn{2}{|c|}{ model 1} & \multicolumn{2}{|c|}{ model 2} & \multicolumn{2}{|c|}{ model 3} & \multicolumn{2}{|c|}{ model 1} & \multicolumn{2}{|c|}{ model 2} & \multicolumn{2}{|c|}{ model 3} \\
\hline & $.098^{* *}$ & .032 & $.094^{* *}$ & .033 & $.098^{* *}$ & .033 & $.127^{* * *}$ & .031 & $.124^{* * *}$ & .031 & $.127^{* * *}$ & .031 \\
\hline Parental neighbourhood Q3 & $.266^{* * *}$ & .031 & $.264^{* * *}$ & .032 & $.266^{* * *}$ & .032 & $.304^{* * *}$ & .030 & $.302^{* * *}$ & .030 & $.303^{* * *}$ & .030 \\
\hline Parental neighbourhood Q4 & $.620^{* * *}$ & .031 & $.620^{* * *}$ & .031 & $.628^{* * *}$ & .031 & $.650^{* * *}$ & .029 & $.649^{* * *}$ & .029 & $.655^{* * *}$ & .029 \\
\hline Parental neighbourhood Q5 & $3.197^{* * *}$ & .030 & $3.626^{* * *}$ & .032 & $3.591^{* * *}$ & .033 & $2.785^{* * *}$ & .029 & $3.199^{* * *}$ & .030 & $3.187^{* * *}$ & .031 \\
\hline Male & $.207^{* * *}$ & .018 & $.210^{* * *}$ & .018 & $.208^{* * *}$ & .018 & $.198^{* * *}$ & .017 & $.201^{* * *}$ & .017 & $.201^{* * *}$ & .017 \\
\hline Single & $.580^{* * *}$ & .009 & $.585^{* * *}$ & .009 & $.584^{* * *}$ & .009 & $.540^{* * *}$ & .007 & $.547^{* * *}$ & .007 & $.545^{* * *}$ & .007 \\
\hline Ethnic minority & $.424^{* * *}$ & .030 & $.424^{* * *}$ & .030 & $.191^{* * *}$ & .041 & $.614^{* * *}$ & .029 & $.612^{* * *}$ & .029 & $.308^{* * *}$ & .038 \\
\hline High education (ref = low) & $-.112^{* * *}$ & .011 & $.301^{* * *}$ & .013 & $.299^{* * *}$ & .013 & $-.434^{* * *}$ & .009 & $-.086^{* * *}$ & .010 & $-.122^{* * *}$ & .011 \\
\hline Log income (1 000 EUR) & $-.036^{* * *}$ & .005 & $-.037^{* * *}$ & .005 & $-.036^{* * *}$ & .005 & $-.157^{* * *}$ & .004 & $-.161^{* * *}$ & .004 & $-.158^{* * *}$ & .004 \\
\hline Rent (ref = homeowner) & $.418^{* * *}$ & .009 & $.417^{* * *}$ & .009 & $.418^{* * *}$ & .009 & $.419^{* * *}$ & .007 & $.415^{* * *}$ & .007 & $.419^{* * *}$ & .007 \\
\hline Age & $-.091^{* * *}$ & .002 & $-.091^{* * *}$ & .002 & $-.091^{* * *}$ & .002 & $-.059^{* * *}$ & .001 & $-.059^{* * *}$ & .001 & $-.058^{* * *}$ & .001 \\
\hline Log income parents (1 000 EUR) & -.001 & .017 & -.004 & .017 & .001 & .017 & $-.143^{* * *}$ & .016 & $-.148^{* * *}$ & .016 & $-.140^{* * *}$ & .016 \\
\hline Parental Q5*high education & & & $-1.377^{* * *}$ & .024 & $-1.491^{* * *}$ & .025 & & & $-1.190^{* * *}$ & .019 & $-1.305^{* * *}$ & .020 \\
\hline Parental Q5*ethnic minority & & & & & $.340^{* * *}$ & .063 & & & & & $.226^{* * *}$ & .060 \\
\hline High education*ethnic minority & & & & & -.019 & .051 & & & & & $.434^{* * *}$ & .039 \\
\hline Parental Q5*high education*ethnic minority & & & & & $.982^{* * *}$ & .079 & & & & & $.753^{* * *}$ & .061 \\
\hline _cons & $-1.603^{* * *}$ & .073 & $-1.725^{* * *}$ & .074 & $-1.741^{* * *}$ & .074 & $-1.391^{* * *}$ & .064 & $-1.489^{* * *}$ & .064 & $-1.515^{* * *}$ & .064 \\
\hline $\mathrm{N}$ & 119167 & & 119167 & & 119167 & & 119167 & & 119167 & & 119167 & \\
\hline N. obs & 953336 & & 953336 & & 953336 & & 1668338 & & 1668338 & & 1668338 & \\
\hline Prob $>$ chi $^{2}$ & .0000 & & .0000 & & .0000 & & .0000 & & .0000 & & .0000 & \\
\hline Nagelkerke $R^{2}$ & .066 & & .073 & & .074 & & .065 & & .070 & & .071 & \\
\hline
\end{tabular}

${ }^{*} p<0.05,{ }^{* *} p<0.01,{ }^{* * *} p<0.001$ 
In support of our main hypothesis, the results further show that the likelihood of residence in poverty concentration is indeed lower for individuals who have attained higher education, and substantially higher for individuals belonging to an ethnic minority group. Both effects increase over time, which indicates that personal attributes and attainments indeed play an increasingly important role in determining personal neighbourhood outcomes over the life course. We find negative significant interaction effects between the deprived parental neighbourhood (quintile 5) and the attainment of higher education throughout the models. These results thus indicate that the negative effect of a parental neighbourhood with a high concentration of poverty on personal residential outcomes is weaker for individuals with a high education. As shown in table $\mathrm{V}$, the moderating effect of personal educational attainment becomes stronger over time. These results thus lends support to our expectation that positive accumulation of individual socioeconomic resources over the life course, in this case higher education, can greatly weaken and potentially discontinue intergenerational transmission of deprived neighbourhood characteristics over time. Furthermore, this effect is shown to differ depending on the individuals' ethnic background. Graph I displays the plot for the three-way interaction included from model 3 onwards, between the deprived parental neighbourhood; individuals' personal educational attainment; and whether the individual belongs to an ethnic minority.

Graph I. Three-way interaction effect plot after multilevel logit regression for 2012. Interaction between the deprived parental neighbourhood, educational attainment, and whether an individual belongs to an ethnic minority group

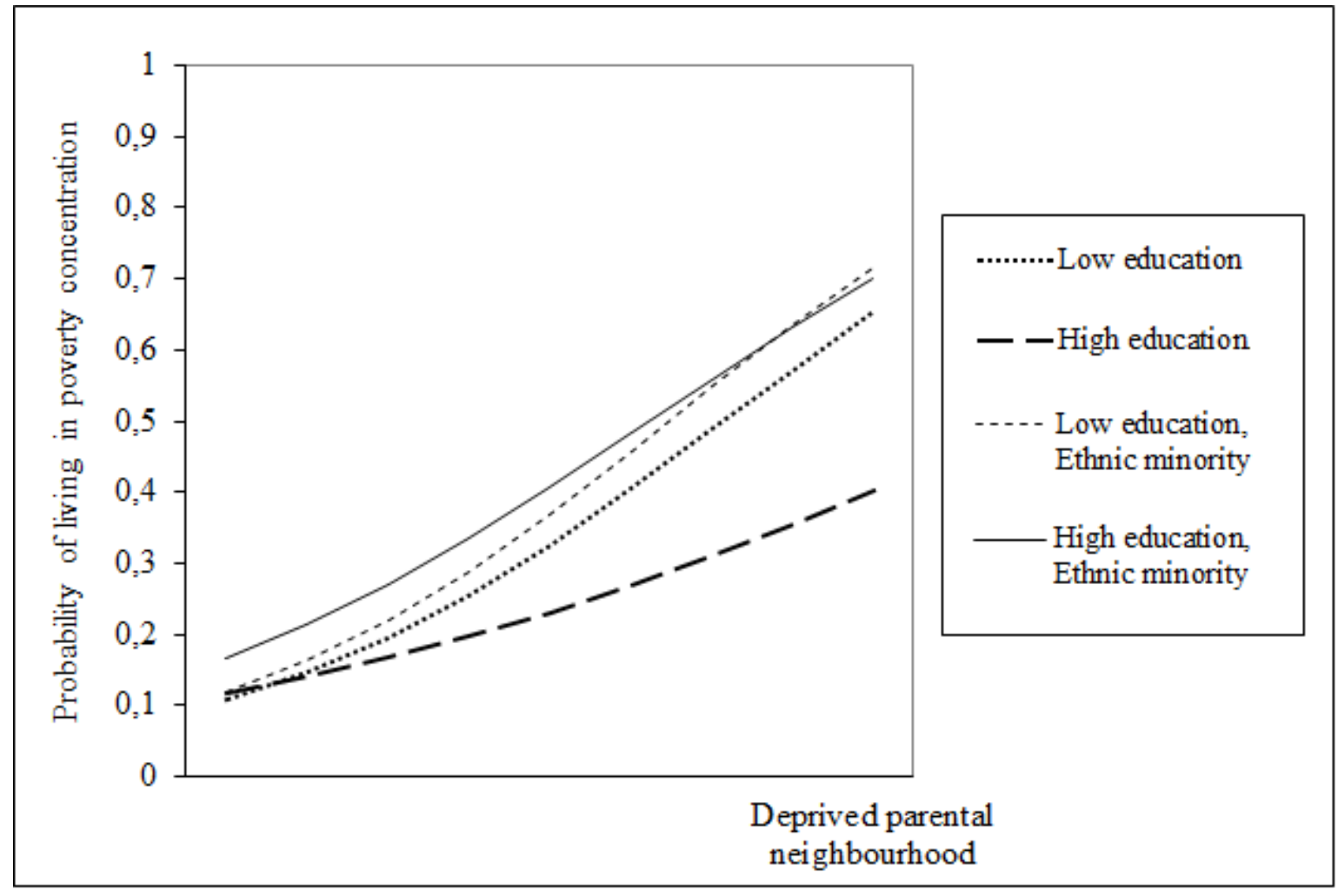

The graph clearly shows that the positive effect of a deprived parental neighbourhood on personal residence in an impoverished area over the measurement period, is most strongly moderated by educational attainment for individuals who do not belong to an ethnic minority group. This result is displayed in the slope of the long dashed line, which is significantly less steep than those of the other category combinations. In fact, the difference in probability of 
residing in a poverty neighbourhood for ethnic minorities is only very minor for the lower and higher education groups, as seen in the solid and short dashed lines. This leads us to broadly conclude that continued or lengthy residence in a deprived neighbourhood after leaving a deprived parental residential environment is common for ethnic minorities despite their accumulation of positive socioeconomic resources over time, while for others, educational attainment can ensure a move away from poverty concentration by strongly reducing the effect of the parental neighbourhood.

The results in Table $\mathrm{V}$ further show significant effects for most controls added throughout the models. Males are shown to have a higher chance of living in a deprived neighbourhood on average compared to females. This finding may in part be explained by household behaviour, as females commonly start cohabitation and marriage earlier on in life (Statistics Netherlands 2013), and a partner subsequently results in a higher combined spendable income on housing. The fact that singles are shown to have a higher chance of living in poverty concentration supports this latter explanation. Both for individuals' own annual income and the income of their parents, the results in 2012 indicate that the higher the income the lower the risk of residing in a deprived neighbourhood after leaving the parental home. As discussed, a substantial body of literature suggests that the income of the parent is a strong predictor of the income of their children later on in life, and this process could certainly be at play in determining the type of neighbourhood one can afford to live in. Nevertheless, the effect of the deprived parental neighbourhood on individual neighbourhood outcomes holds throughout the analyses, even after adding the control for parental income. We further find that individuals' chance of living in a deprived neighbourhood declines with age, presumably as their income grows, and that individuals in rental accommodation are more likely to experience concentrated poverty than homeowners.

\section{Discussion and conclusions}

In this study, we applied a life course approach to the examination of intergenerational spatial inequality patterns, reinforcing previous arguments for a dynamic, long-term perspective on neighbourhood effects. In doing so, we add to the limited, but growing literature which shows that individual outcomes are not only influenced by the current residential location, but also by previous neighbourhood experiences (Sharkey \& Elwert 2011; van Ham et al. 2014; Sharkey \& Faber 2014). Taking into consideration individuals' long-term residential locations, we were able to examine whether individuals' chances were impaired by where they lived over time. Does growing up in a deprived parental neighbourhood increase individual chances of residing in poverty concentration later in life? At the core of our research into these intergenerational transmission patterns, we hypothesised that individuals' educational attainment, as a personal rather than inherited resource, would become increasingly important to their personal neighbourhood outcomes over time; weakening, or even discontinuing intergenerational spatial inequality patterns over the life course. Additionally, we anticipated that education may be a weaker mediator of an intergenerational neighbourhood effect for ethnic minorities groups compared to other Dutch inhabitants.

Both the descriptive and multivariate analyses results confirm that a deprived parental neighbourhood strongly increases an individual's chances to end up in deprived residential locations, far into adulthood. Furthermore, we find that intergenerational spatial inequality is more prevalent among non-Western ethnic minority groups. The effect of the parental neighbourhood is persistently strong throughout the models, and holds even after adding relevant controls and moderators, thus overarching effects due to variation in individual and household characteristics, as well as parental income levels. Therefore, while ample literature suggests that parental income is a strong predictor of the income and outcomes of their 
children over the life course, and their subsequent neighbourhood selection, the parental neighbourhood itself also appears to play an important role in transmitting neighbourhood characteristics. Additionally, in support of our main hypothesis, the results show that individuals' attainment of higher education indeed reduces the effect of the deprived parental neighbourhood on disadvantageous residential outcomes. Furthermore, when comparing the models over time, we find that the relative importance of higher education as a personal resource becomes stronger, as does its moderation of a parental effect. Interestingly, this main result primarily holds for individuals who do not belong to an ethnic minority. For individuals from a deprived parental neighbourhood and an ethnic minority, the level of education has hardly any effect on their chances of residing in poverty concentration oneself; which are higher than those of other Dutch inhabitants overall, even than those with a lower education. In line with previous research (Vartanian et al. 2007; Sharkey \& Elwert 2011; van Ham et al. 2014), these findings suggest that ethnic minorities are less likely to experience improvements of their residential environment and upward social mobility, even after attaining higher education.

Due to the nature of our data, the fact that it does not include subjective observations, we are not able to further examine the precise causal mechanisms behind intergenerational transmission of deprived neighbourhood characteristics. Explanations can range from complex inter-family and societal processes such as social contagion; a limited network range due to a homogeneous composition of the deprived neighbourhood; or a collective acceptance of dysfunctional norms and values, which affect individual chances to participate in society and experience upward social mobility (for an extensive discussion see Galster 2012). However, people may also choose to live in a certain neighbourhood because they are accustomed to it, since it is similar to the one experienced during childhood. Additionally, individuals may purposely live close to their parents or in a neighbourhood that offers similar facilities and services as the parental neighbourhood (van Ham et al. 2014). For ethnic minority groups in particular, specific services for everyday life, such as supermarkets with international produce or local societies for inhabitants with a similar ethnic background, are often clustered within a small number of neighbourhoods in the larger cities in the Netherlands. The same holds for religious facilities, such as mosques, temples or synagogues. The controls in our models may not serve as sufficient proxies to cover this range of possible considerations behind a selection into a deprived residential neighbourhood after leaving the parental home. This study may thus encourage future research, using subjective observations on what may underlie causal mechanisms at play in the process of intergenerational neighbourhood continuity.

Combined, the results of this study show that intergenerational spatial inequality plays an important role in determining individual residential outcomes over the life course. In this context, to our knowledge, we are the first to explicitly focus on the role of educational attainment in weakening or discontinuing such intergenerational neighbourhood patterns. As such, the results of this study strongly reinforce the contribution that longitudinal, life course research into the residential environment can make to the body of neighbourhood effects literature as well as that of intergenerational transmission of disadvantage. The results indicate that individuals' full neighbourhood history, rather than just their current residential location, must be taken into consideration if researchers wish to draw any meaningful conclusion on whether individuals' chances are impaired by where they live.

\section{Acknowledgements}

The research leading to these results has received funding from the European Research Council under the European Union's Seventh Framework Programme (FP/2007-2013) / ERC Grant Agreement n. 615159 (ERC Consolidator Grant DEPRIVEDHOODS, Socio-spatial 
inequality, deprived neighbourhoods, and neighbourhood effects) and from the Marie Curie programme under the European Union's Seventh Framework Programme (FP/2007-2013) / Career Integration Grant n. PCIG10-GA-2011-303728 (CIG Grant NBHCHOICE, Neighbourhood choice, neighbourhood sorting, and neighbourhood effects).

\section{References}

Aisenbrey, S., \& Fasang, A. E. (2010). New life for old ideas: The" second wave" of sequence analysis bringing the" course" back into the life course. Sociological Methods \& Research, 38(3), 420-462.

Bakker, B. F., van Rooijen, J., \& van Toor, L. (2014). The system of social statistical datasets of Statistics Netherlands: An integral approach to the production of register-based social statistics. Statistical Journal of the IAOS: Journal of the International Association for Official Statistics.

Becker, G. S., \& Tomes, N. (1979). An equilibrium theory of the distribution of income and intergenerational mobility. The Journal of Political Economy, 1153-1189.

Bisin, A., \& Verdier, T. (1998). On the cultural transmission of preferences for social status. Journal of Public Economics, 70(1), 75-97.

Blanden, J., Gregg, P., \& Machin, S. (2005). Intergenerational Mobility in Europe and North America. London. London School of Economics. Centre for Economic Performance.

Bloome, D. (2014). Racial Inequality Trends and the Intergenerational Persistence of Income and Family Structure. American Sociological Review, 79(6), 1196-1225, doi:10.1177/0003122414554947.

Brooks-Gunn, J., Duncan, G., \& Aber, J. L. (1997a). Neighborhood poverty, volume 1: Context and consequences for children: Russell Sage Foundation.

Brooks-Gunn, J., Duncan, G., \& Aber, J. L. (1997b). Neighborhood Poverty, volume 2: Policy Implications in Studying Neighborhoods: Russell Sage Foundation.

Brzinsky-Fay, C., Kohler, U., \& Luniak, M. (2006). Sequence analysis with Stata. Stata Journal, 6(4), 435.

Buck, N. (2001). Identifying Neighbourhood Effects on Social Exclusion. Urban Studies, 38(12), 2251-2275, doi:10.1080/00420980120087153.

Clark, W. A., Deurloo, M. C., \& Dieleman, F. M. (2003). Housing careers in the United States, 1968-93: Modelling the sequencing of housing states. Urban Studies, 40(1), 143-160.

Clark, W. A., \& Huang, Y. (2003). The life course and residential mobility in British housing markets. Environment and Planning A, 35(2), 323-340.

Clark, W. A., \& Ledwith, V. (2005). Mobility, housing stress and neighborhood contexts: evidence from Los Angeles. California Center for Population Research.

Coulter, R., \& van Ham, M. (2013). Following People Through Time: An Analysis of Individual Residential Mobility Biographies. Housing Studies, 28(7), 1037-1055, doi:10.1080/02673037.2013.783903.

Crowder, K., \& South, S. J. (2003). Neighborhood distress and school dropout: the variable significance of community context. Social Science Research, 32(4), 659-698, doi:http://dx.doi.org/10.1016/S0049-089X(03)00035-8.

Crowder, K., \& South, S. J. (2005). Race, Class, and Changing Patterns of Migration between Poor and Nonpoor Neighborhoods1. American Journal of Sociology, 110(6), 17151763.

D'Addio, A. C. (2007). Intergenerational transmission of disadvantage: mobility or immobility across generations?: a review of the evidence for OECD countries. 
Dietz, R. D. (2002). The estimation of neighborhood effects in the social sciences: An interdisciplinary approach. Social Science Research, 31(4), 539-575, doi:http://dx.doi.org/10.1016/S0049-089X(02)00005-4.

Durlauf, S. N. (2004). Chapter 50 Neighborhood effects. In J. V. Henderson, \& T. JacquesFrançois (Eds.), Handbook of Regional and Urban Economics (Vol. Volume 4, pp. 2173-2242): Elsevier.

Dykstra, P. A., \& van Wissen, L. J. (1999). Introduction: The life course approach as an interdisciplinary framework for population studies. In Population Issues (pp. 1-22): Springer.

Ellen, I. G., \& Turner, M. A. (1997). Does neighborhood matter? Assessing recent evidence. Housing Policy Debate, 8(4), 833-866, doi:10.1080/10511482.1997.9521280.

Feijten, P. (2005). Life events and the housing career: A retrospective analysis of timed effects: Eburon Delft.

Feijten, P., Hooimeijer, P., \& Mulder, C. H. (2008). Residential experience and residential environment choice over the life-course. Urban Studies, 45(1), 141-162.

Feijten, P., \& Mulder, C. H. (2005). Life-course experience and housing quality. Housing Studies, 20(4), 571-587.

Friedrichs, J. r., \& Blasius, J. r. (2003). Social norms in distressed neighbourhoods: testing the Wilson hypothesis. Housing Studies, 18(6), 807-826, doi:10.1080/0267303032000135447.

Galster, G. (2002). An economic efficiency analysis of deconcentrating poverty populations. Journal of Housing Economics, 11(4), 303-329, doi:http://dx.doi.org/10.1016/S10511377(02)00122-5.

Galster, G., Andersson, R., \& Musterd, S. (2010). Who Is Affected by Neighbourhood Income Mix? Gender, Age, Family, Employment and Income Differences. Urban Studies, 47(14), 2915-2944, doi:10.1177/0042098009360233.

Galster, G., Cutsinger, J., \& Lim, U. (2007). Are Neighbourhoods Self-stabilising? Exploring Endogenous Dynamics. Urban Studies, 44(1), 167-185, doi:10.1080/00420980601023851.

Galster, G. C. (2012). The Mechanism(s) of Neighbourhood Effects: Theory, Evidence, and Policy Implications. In M. van Ham, D. Manley, N. Bailey, L. Simpson, \& D. Maclennan (Eds.), Neighbourhood Effects Research: New Perspectives (pp. 23-56): Springer Netherlands.

Geist, C., \& McManus, P. A. (2008). Geographical mobility over the life course: Motivations and implications. Population, Space and Place, 14(4), 283-303.

Giele, J. Z., \& Elder, G. H. (1998). Methods of life course research: Qualitative and quantitative approaches: Sage Publications.

Hedman, L., Manley, D., van Ham, M., \& Östh, J. (2013). Cumulative exposure to disadvantage and the intergenerational transmission of neighbourhood effects. Journal of Economic Geography, doi:10.1093/jeg/lbt042.

Helderman, A., \& Mulder, C. (2007). Intergenerational transmission of homeownership: The roles of gifts and continuities in housing market characteristics. Urban Studies, 44(2), 231-247.

Kunz, J., Page, M. E., \& Solon, G. (2003). Are point-in-time measures of neighborhood characteristics useful proxies for children's long-run neighborhood environment? Economics Letters, 79(2), 231-237.

Kurz, K. (2004). Labour Market Position, Intergenerational Transfers and Home-ownership A Longitudinal Analysis for West German Birth Cohorts. European Sociological Review, 20(2), 141-159. 
Manley, D., van Ham, M., Bailey, N., Simpson, L., \& Maclennan, D. (2013). Neighbourhood Effects or Neighbourhood Based Problems? A Policy Context. In D. Manley, M. van Ham, N. Bailey, L. Simpson, \& D. Maclennan (Eds.), Neighbourhood Effects or Neighbourhood Based Problems? (pp. 1-23): Springer Netherlands.

Musterd, S., Galster, G., \& Andersson, R. (2012). Temporal dimensions and measurement of neighbourhood effects. Environment and Planning-Part A, 44(3), 605.

Overman, H. G. (2002). Neighbourhood Effects in Large and Small Neighbourhoods. Urban Studies, 39(1), 117-130, doi:10.1080/00420980220099104.

Quillian, L. (2003). How Long are Exposures to Poor Neighborhoods? The Long-Term Dynamics of Entry and Exit from Poor Neighborhoods. Population Research and Policy Review, 22(3), 221-249, doi:10.1023/a:1026077008571.

Sampson, R. J., Morenoff, J. D., \& Gannon-Rowley, T. (2002). Assessing "Neighborhood Effects": Social Processes and New Directions in Research. Annual Review of Sociology, 28(ArticleType: research-article / Full publication date: 2002 / Copyright (C) 2002 Annual Reviews), 443-478, doi:10.2307/3069249.

Sharkey, P., \& Elwert, F. (2011). The legacy of disadvantage: Multigenerational neighborhood effects on cognitive ability. AJS; American journal of sociology, 116(6), 1934.

Sharkey, P., \& Faber, J. W. (2014). Where, when, why, and for whom do residential contexts matter? Moving away from the dichotomous understanding of neighborhood effects. Annual Review of Sociology(0).

Simpson, L., \& Finney, N. (2009). Spatial patterns of internal migration: evidence for ethnic groups in Britain. Population, Space and Place, 15(1), 37-56.

Simpson, L., Purdam, K., Tajar, A., Fieldhouse, E., Gavalas, V., Tranmer, M., et al. (2006). Ethnic minority populations and the labour market: an analysis of the 1991 and 2001 Census. London: DWP Report No. 33.

Small, M. L., \& Feldman, J. (2012). Ethnographic evidence, heterogeneity, and neighbourhood effects after moving to opportunity. In Neighbourhood effects research: New perspectives (pp. 57-77): Springer.

Solon, G. (2002). Cross-country differences in intergenerational earnings mobility. The Journal of Economic Perspectives, 16(3), 59-66.

South, S. J., \& Crowder, K. D. (1997). Escaping distressed neighborhoods: Individual, community, and metropolitan influences. American Journal of Sociology, 1040-1084.

StatisticsNetherlands (2013). Huwen en partnerschapsregistratie; kerncijfers. http://statline.cbs.nl.

van der Klaauw, B., \& van Ours, J. C. (2003). From welfare to work: does the neighborhood matter? Journal of Public Economics, 87(5-6), 957-985, doi:http://dx.doi.org/10.1016/S0047-2727(01)00133-5.

van Ham, M., Hedman, L., Manley, D., Coulter, R., \& Östh, J. (2014). Intergenerational transmission of neighbourhood poverty: an analysis of neighbourhood histories of individuals. Transactions of the Institute of British Geographers, 39(3), 402-417, doi:10.1111/tran.12040.

van Ham, M., \& Manley, D. (2012). Neighbourhood effects research at a crossroads. Ten challenges for future research. Environment and Planning A, 44(12), 2787-2793.

Vartanian, T. P., Walker Buck, P., \& Gleason, P. (2007). Intergenerational NeighborhoodType Mobility: Examining Differences between Blacks and Whites. Housing Studies, 22(5), 833-856, doi:10.1080/02673030701474792.

Wilson, W. J. (2012 [1987]). The truly disadvantaged: The inner city, the underclass, and public policy. Chicago: University of Chicago Press. 